Original Article

\title{
PATENT MEDICINE VENDORS' PREPAREDNESS AND RESPONSE FOR THE PREVENTION AND CONTROL OF COVID-19 INFECTION IN A NORTH-CENTRAL STATE IN NIGERIA
}

\author{
OLAYINKA S. ILESANMI ${ }^{1,2}$, AANUOLUWAPO A. AFOLABI ${ }^{1}$, OLUWATOSIN E. FAKAYODE ${ }^{3}$
}

${ }^{1}$ Department of Community Medicine, College of Medicine, University of Ibadan, Oyo State, Nigeria, ${ }^{2}$ Department of Community Medicine, University College Hospital, Ibadan, Oyo State, Nigeria, ${ }^{3}$ Department of Public Health, State Ministry of Health, Ilorin, Kwara State, Nigeria Email: ileolasteve@gmail.com

Received: 24 Oct 2020, Revised and Accepted: 11 Nov 2020

ABSTRACT

Objective: This report aimed to determine the immediate effect of the IPC training on the knowledge and role of patent medicine vendors (PMV) in the COVID-19 outbreak response in Nigeria.

Methods: We conducted a quasi-experimental study before and after the IPC training among 1076 PMV in Ilorin, Kwara state, Nigeria. Data analysis was done using SPSS version 23. Eight questions were asked, for which each was assigned a score of " 1 ". Participants who had scored $<50 \%$ were categorized as "Fail", while those with scores $250 \%$ were categorized as "Pass" in both the pre and post -tests. The Chi-square test was used to test for the association between sociodemographic characteristics and performance of respondents in the pre-and post-IPC knowledge results, and paired t-test to test for significant differences between the pre and post-tests mean scores. The level of significance was set at $p<0.05$ for all statistical tests.

Results: The mean age of the 1076 respondents was $37.06 \pm 10.96,463(43 \%)$ passed the pre-test, while 617 (57.3\%) passed the post-test. The mean pre-test IPC training score was $3.1310 \pm 1.5631$, while the mean post-test IPC training score was $3.7351 \pm 1.6028(\mathrm{t}=-11.337$, $\mathrm{p}=<0.001)$. In all, $617(57.3 \%)$ scored higher in posttest. Overall, 560 (92.41\%) identified community sensitization and health education on COVID-19 preventive measures as roles of PMV.

Conclusion: Regular trainings on COVID-19 preventive practices among PMV should be conducted. PMV should be empowered to sensitize and educate their clients on the prevention of COVID-19.

Keywords: COVID-19, Patent medicine vendors, Infection prevention and control, COVID-19 prevention and control, Nigeria

(C) 2020 The Authors. Published by Innovare Academic Sciences Pvt Ltd. This is an open access article under the CC BY license (http://creativecommons.org/licenses/by/4.0/) DOI: http://dx.doi.org/10.22159/ijpps.2020v12i12.40097. Journal homepage: https://innovareacademics.in/journals/index.php/ijpps.

Speedy peer review was done as the subject of the manuscript was related with pandemic.

\section{INTRODUCTION}

The Coronavirus (COVID-19) pandemic has necessitated a change in the delivery of health services from the traditional manner of careseeking from hospitals only [1-3]. Care-seeking for both emergency and non-emergency cases during the COVID-19 outbreak has placed an increased burden on healthcare workers and health facilities [1, 2 , 4]. Of the 48,171,563 COVID-19 cases globally, Africa accounts for nearly $0.13 \%$ and 63328 cases have been recorded in Nigeria as of 5th November 2020, and health facilities are becoming inadequate in managing patients [5]. The gross inadequacy of the health facilities has therefore posited that the available human resources for health is insufficient to cater for the teeming population of nearly 206 million population of Nigeria [6]. Prior to the COVID-19 pandemic, Nigeria's health workforce was estimated at 2.23 per 1000 population, a value which falls below the 4.45 health workforce per 1000 population recommended by the World Health Organization [7]. The shortage of health manpower has persisted into the COVID-19 context and promoted navigation towards homebased care of COVID-19 cases [8]. This array of evidence therefore necessitates a response from the private or public sector, formal or informal, for an improved response during the COVID-19 pandemic. In this regard, the roles of patent medicine vendors (PMV) cannot be over-emphasized.

The PMV are key informal providers of healthcare in communities in developing countries [9-11]. In Nigeria, PMV has contributed to the reduction in malarial burden, childhood diarrhea, and the enhancement of health education and promotion, infection prevention, and control practices at community levels, and boost linkage to the national health system when required [11-13]. Building on these successes, PMV occupy a focal point for tackling the COVID-19 pandemic at the community level [14]. The increasing community-wide transmission of COVID-19 further approves of the need to engage PMV in the COVID-19 response strategy [15]. To the best of our knowledge, no study has been conducted in Nigeria on the role of PMV in the COVID-19 response. A study of this regard would be important in the implementation of a national plan to deliver quality-assured community-centered health service in the COVID-19 response through the inclusion of PMV. Therefore, this study aimed to assess the roles of PMV in the COVID-19 response in a North-Central State in Nigeria.

\section{MATERIALS AND METHODS}

Study area

Kwara state, one of the 36 states in Nigeria, was created in 1967 when 12 states were created from Nigeria by the military government. Kwara state occupies 33,433kilometre square land area and is made up of more than 100 towns and villages [16] Kwara state is bounded by Benin to the West, Kogi to the East, Ekiti, Osun, and Oyo to the South, and Niger state to the North. Kwara State is administratively organized at the state and LGA levels with 16 LGAs $[17,18]$. Patent medicine stores are readily available across the LGA in Kwara state. Ethical approval for the study was obtained from the Institutional Review Board of the National Institute of Medical Research, Lagos, Nigeria (Ref No: IRB/20/048).

\section{Study population}

The participants were 1076 PMV from 14 out of the 16 LGAs in Kwara State. The enrolled LGAs included: Ilorin South, Ilorin East, Irepodun, Ilorin West, Ifelodun, Oke-Ero, Oyun, Moro, Offa, Isin, Patigi, Asa, Edu, and Ekiti. Informed consent was obtained from each PMV, and confidentiality of personal information was assured. No harm was inflicted on participants as a result of participating in this study. 


\section{Study design}

We conducted a quasi-experimental, before-and-after the IPC training which was held at the Pharmacists' House, Kwara Hotels, Ilorin, Kwara state in September, 2020. All participants were included, and questionnaires with missing fields were excluded from this study. Resource persons included COVID-19 response team members in Kwara state who had participated in a trainers' training regarding the management of the COVID-19 outbreak. The training agenda and materials provided by the Nigeria Center for Disease Control (NCDC) were adapted for this study. The training consisted of didactic lectures, interactive sessions, and role-plays. We obtained information on participants' sociodemographic characteristics, years of experience, the average number of customers, the highest level of education, years of practice, and whether IPC training had been received previously. We conducted pre-and post-tests using questions covering the training topics.

\section{Training topics}

The training topics were divided into 5 sections. The first topic, Basics of COVID-19, included lessons on the history of Coronaviruses, definition and emergence of COVID-19, modes of transmission, COVID19 risk factors, COVID-19 vulnerable population, such as the elderly and persons with underlying health conditions e. g. diabetes, and an overview of recommended guidelines for self-protection from COVID19 , such as social distancing.

The second topic, "Standard infection prevention and control (IPC) precautions", included measures for the prevention and control of COVID-19. The IPC precautions taught included the use of face masks and gloves and disinfection of surfaces and the environment. The practice of hand hygiene should be maintained prior to the use of any personal protective equipment (PPE) was reiterated in many instances. The PMV was taught the appropriate method for donning and doffing of face masks and gloves, and the avoidance of contact with the outward surface of both face masks and gloves. Also, lessons were taught on covering the bridge of the nose and the chin respectively with the upper and lower ends of the face mask.

The third topic, "Demonstration of the 5 moments of hand hygiene," entailed observing hand hygiene before touching a suspected or positive case of COVID-19, before conducting clean/aseptic procedures, after exposure to the risk of body fluid, after touching a suspected or positive case of COVID-19, and after touching the surrounding of such individuals. The appropriate modalities for practicing hand hygiene using either soap and clean water or alcohol-based hand rubs were also demonstrated. The hand rubs are to be prepared with $70 \%$ alcohol content for effective cleanliness. After each session of handwashing with soap and water, the hands should be dried using disposable napkins or tissue papers.

The fourth topic, "Management of healthcare waste generated," included the method of disposing of used PPE after each use. Such wastes generated should be handled as infectious wastes and properly discarded in tight-fitted thrash bins to rule out the possibility of being picked by children in the community. Recycling of face masks could also be done through washing them in a chlorine solution after each use.

The fifth topic, "Detailed knowledge of the COVID-19 outbreak response in Kwara state" described the COVID-19 situation in Kwara state, including information on the hot-spot communities within the state. It also included lessons on the outbreak response team, and notification officers for suspected cases of COVID-19.

\section{Data collection, management, and analysis}

We analyzed the data using SPSS, version 23. Overall, eight questions were asked, and each question was assigned a score of "1" for correct responses. We computed participants' scores at the preand post-tests, as well as the mean, median, and the range of scores obtained. A maximum obtainable score of $100 \%$ was calculated using the aggregate scores. Participants who had scored $<50 \%$ were categorized as "Fail", while those with $\geq 58$ erreswere categorized as "Pass" in both the pre and post-tests. The Chi-square test was used to test for the difference between the proportion of study participants who had passed both the pre and post-tests. In addition, we used the paired t-test to test for significant differences between the pre and post-tests mean scores. We also assessed the association between sociodemographic characteristics and pre and post-tests knowledge scores. The level of significance was set at $\mathrm{p}<0.05$ for all statistical tests.

\section{RESULTS}

Table 1 shows the sociodemographic characteristics of patent medicine vendors. The mean age of the 1076 respondents was $37.06 \pm 10.96$. Among them, 348 (32.3\%) were males, 295 (27.4\%) were below $30 \mathrm{y}, 364(36.5 \%)$ had spent more than $10 \mathrm{y}$ in practice as patent medicine vendors. Among them, 298 (27.7\%) had received previous IPC training (table 1). Also, 97(9.0\%) were from Ilorin South, 95(8.8\%) from Ilorin East, $90(8.4 \%)$ from Irepodun, and $89(8.3 \%)$ were from Ilorin West LGAs (fig. 1).

Table 1: Sociodemographic characteristics of patent medicine vendors

\begin{tabular}{lll}
\hline Variable & Frequency & \% \\
\hline Sex & 348 & 32.3 \\
Male & 728 & 67.7 \\
Female & & \\
Age group (years) & 295 & 27.4 \\
$<30$ & 370 & 34.4 \\
$30-39$ & 234 & 21.7 \\
$40-49$ & 177 & 16.4 \\
$\geq 50$ & & \\
Highest level of education & 639 & 59.4 \\
Secondary & 437 & 40.6 \\
Tertiary & & \\
Years of Practice & 712 & 66.2 \\
$\leq 10$ & 364 & 33.8 \\
$>10$ & & \\
Average daily customers & 556 & 51.7 \\
$\leq 15$ & 520 & 48.3 \\
$>15$ & & 27.7 \\
Received previous IPC training? & 298 & 72.3 \\
Yes & 778 & \\
No & & \\
\hline
\end{tabular}

Among the PMV, 166 (47.7\%) males passed the pre-test compared to $297(40.8 \%)$ females $\left(\mathrm{X}^{2}=4.579, \mathrm{p}<0.032\right)$, while $138(39.7 \%)$ males passed the post-test compared to 321 (44.4\%) females
$\left(\mathrm{X}^{2}=1.896, \mathrm{p}=0.169\right)$, though the difference was not significant statistically. Also, 116 (39.3\%) of respondents below 30 y passed the pre-test compared to other age groups $\left(\mathrm{X}^{2}=6.831, \mathrm{p}=0.033\right)$, and 156 
(52.9\%) passed the post-test $\left(\mathrm{X}^{2}=12.476, \mathrm{p}=0.002\right)$. Further, 254 $(39.7 \%)$ respondents with secondary education passed the pre-test compared to $209(47.8 \%)$ with tertiary education $\left(X^{2}=6.906\right.$, $\mathrm{p}=0.009)$, and $348(54.5 \%)$ with secondary education passed the post-test compared to $269(61.6 \%)$ with tertiary education $\left(\mathrm{X}^{2}=5.342, \mathrm{p}=0.021\right)($ table 2$)$.

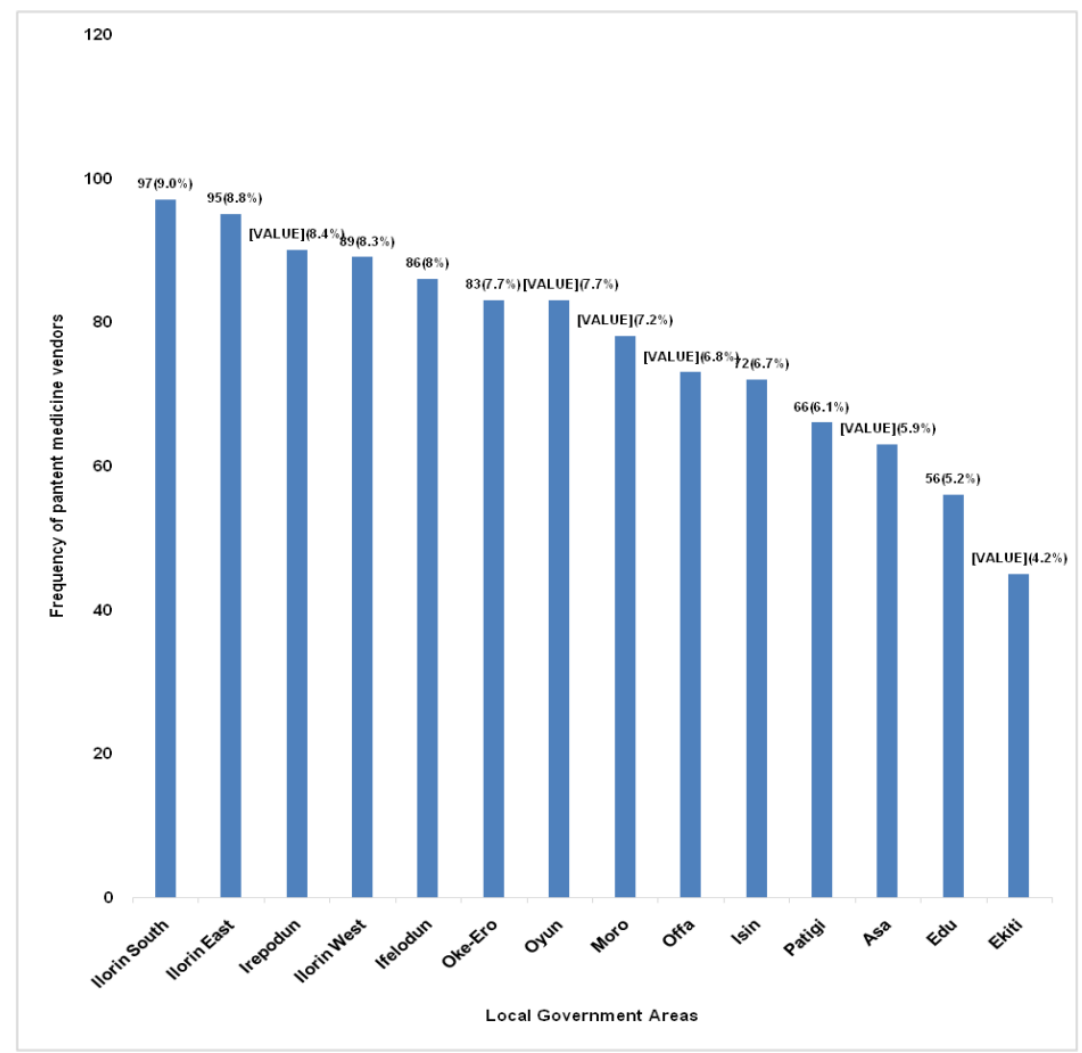

Fig. 1: Geographical distribution of patent medicine vendors at the IPC training program

Table 2: Association between sociodemographic characteristics and performance of patent medicine vendors in the pre-and post-IPC training results

\begin{tabular}{|c|c|c|c|c|}
\hline \multirow[t]{2}{*}{ Characteristics } & \multicolumn{2}{|l|}{ Pre-test } & \multicolumn{2}{|l|}{ Post-test } \\
\hline & Pass n (\%) & Fail n (\%) & Pass n (\%) & Fail n (\%) \\
\hline \multicolumn{5}{|l|}{ Sex } \\
\hline Male & $166(47.7)$ & $182(52.3)$ & $210(60.3)$ & 138(39.7) \\
\hline \multirow[t]{2}{*}{ Female } & $297(40.8)$ & $431(59.2)$ & $407(55.9)$ & $321(44.4)$ \\
\hline & $\mathrm{X}^{2}=4.579 \mathrm{p}=0$ & & $X^{2}=1.896 p=c$ & \\
\hline \multicolumn{5}{|c|}{ Age Group (years) } \\
\hline$<30$ & $116(39.3)$ & $179(60.7)$ & $156(52.9)$ & $139(47.1)$ \\
\hline $30-49$ & $256(42.4)$ & $348(57.6)$ & $339(56.1)$ & $265(43.9)$ \\
\hline \multirow[t]{2}{*}{$\geq 50$} & $91(51.4)$ & $86(48.6)$ & $122(68.9)$ & $55(31.1)$ \\
\hline & $\mathrm{X}^{2}=6.831 \mathrm{p}=\mathrm{C}$ & & $\mathrm{X}^{2}=12.476 \mathrm{p}=$ & \\
\hline \multicolumn{5}{|c|}{ Highest level of education } \\
\hline Secondary & 254(39.7) & $385(60.3)$ & $348(54.5)$ & $291(45.5)$ \\
\hline \multirow[t]{2}{*}{ Tertiary } & $209(47.8)$ & $228(52.2)$ & $269(61.6)$ & $168(38.4)$ \\
\hline & $\mathrm{X}^{2}=6.906 \mathrm{p}=\mathrm{C}$ & & $X^{2}=5.342 p=c$ & \\
\hline \multicolumn{5}{|l|}{ Years of Practice } \\
\hline$\leq 10$ & $282(39.6)$ & $430(60.4)$ & $399(56)$ & $313(44)$ \\
\hline \multirow[t]{2}{*}{$>10$} & $181(49.7)$ & $183(50.3)$ & $218(59.9)$ & $146(40.1)$ \\
\hline & $X^{2}=10.060 p=$ & & $\mathrm{X}^{2}=0.121 \mathrm{p}=\mathrm{C}$ & \\
\hline \multicolumn{5}{|c|}{ Average daily customers* } \\
\hline$\leq 15$ & $214(38.5)$ & $312(61.5)$ & $316(56.8)$ & $240(43.2)$ \\
\hline \multirow[t]{2}{*}{$>15$} & $249(47.9)$ & $271(52.1)$ & $301(57.9)$ & $219(42.1)$ \\
\hline & $X^{2}=9.676 p=($ & & $\mathrm{X}^{2}=4.579 \mathrm{p}=\mathrm{C}$ & \\
\hline \multicolumn{5}{|c|}{ Had previous IPC training } \\
\hline Yes & $127(42.6)$ & $171(57.4)$ & $164(55)$ & $134(45)$ \\
\hline \multirow[t]{2}{*}{ No } & $336(43.2)$ & $442(56.8)$ & $453(58.2)$ & $325(41.8)$ \\
\hline & $X^{2}=0.029 p=($ & & $\mathrm{X}^{2}=0.898 \mathrm{p}=\mathrm{C}$ & \\
\hline
\end{tabular}

Among the respondents, $463(43 \%)$ passed the pre-test, while $617(57.3 \%)$ passed the post-test. The mean pre-test IPC training score was $3.1310 \pm 1.5631$, while the mean post-test IPC training score was $3.7351 \pm 1.6028(\mathrm{t}=-11.337, \mathrm{p}=<0.001)$. In all, 617(57.3\%) scored higher in posttest. A weak positive correlation was found between the pre-and post-IPC training test scores ( $r=0.328, p=<0.001, N=1076)$ (table 3). 
Among the respondents, 606 (56.3\%) identified that patent medicine vendors had roles to play in the prevention of COVID-19. Of the 606 responses obtained in this regard, 560 (92.41\%) identified community sensitization and health education on COVID-
19 preventive measures as roles of PMV. Also, 46 (7.59\%) stated the roles of patent medicine vendors in the COVID-19 outbreak to include active case search and linking of community members to COVID-19 testing and care.

Table 3: Results of COVID-19 IPC training among patent medicine vendors in Kwara state

\begin{tabular}{llll}
\hline Respondents' performance & Pre-test n (\%) & Post-test n (\%) & Test-statistic; p-value \\
\hline Pass & $463(43)$ & $617(57.3)$ & $\mathrm{X}^{2}=44.062 ; \mathrm{p}=<0.001$ \\
Fail & $613(57)$ & $459(32.7)$ & \\
mean \pm SD & $3.1310 \pm 1.5631(68.1)$ & $3.7351 \pm 1.6028(57.3)$ \\
Median & 3.00 & 4.00 & $0-8$ \\
Range & $0-7$ & $\mathrm{t}=-11.337 ; \mathrm{p}=<0.001$ \\
\hline
\end{tabular}

\section{DISCUSSION}

We found a significant association between the age group of PMV and the IPC training pre-test and post-test performance. Individuals in the older age group performed better than their counterparts in the younger age group in both pre and post-test scores. This finding, therefore, highlights an increased likelihood for acquiring knowledge with increasing age. Similarly, as the years of PMV increase, so does the number of years spent in practice and likewise the average number of daily customers. An increase in the number of customers had significant effects on the pre and post-tests scores. This finding suggests that the average daily customers attended to results to an increase in the knowledge of PMV, which is primarily due to numerous customer-PMV attendant interactions regarding various illnesses. In addition, attainment of a higher level o education similarly increased the pre and post-test performance. Such improvement stems from patient satisfaction, which results in an increased number of daily customers. This finding is akin to the reports from other studies [12, 13]. The consonance between the findings in this study and reference literature reiterate that increasing average customers results to an increasing stock of medications in patent medicine stores, and ultimately an increased opportunity for patients' care.

We identified certain roles to be played by PMV during the COVID19 pandemic. The effective engagement of PMV in any health response is largely determined by the identification of their potential roles [12]. We found that community sensitization is a key role to be conducted by PMV. This is because PMV could build on their adequate understanding of community members and the terrain to mobilize stakeholders for health education regarding COVID-19. The involvement of PMV and other professionals have been described as laudable efforts for the prevention of COVID19[18]. In this regard, trainings on the structure, content, and modalities for delivering health education and public health campaigns need to be conducted for PMV. Also, scheduled regular evaluation of trainings need to be conducted to keep PMV abreast of their roles on the health education of community members.

In addition, PMV could serve as focal persons to conduct an active case search of suspected COVID-19 cases. Due to the existing relationship between PMV and community members, PMV could suitably function as COVID-19 case notification officers to enable timely detection of COVID-19 cases, and limit further transmission of COVID-19 among community members. In addition, the active engagement of PMV who residents of the communities are often where they practice fosters the trust of other community members in the COVID-19 containment efforts currently implemented by the government. Linkage of community members to COVID-19 testing centers could then be possible in such a manner as to reduce the inherent inequalities in accessing care in the Nigerian health system. Evidence of the feats done through the active engagement of PMV has been demonstrated in events of malaria treatment, effective management of diarrhea, and increased uptake of health insurance[10,19,20]. Therefore, PMV should be appropriately harnessed as a vital human resource for the prevention and control of COVID-19.

\section{STRENGTHS}

The training was conducted by seasoned resource persons, and the NCDC guidelines were made use of.

\section{LIMITATIONS}

The limited period within which the training was conducted could have limited the knowledge of the PMV who attended the training. All the 16 LGAs in Kwara state were not represented by the PMV in attendance at the IPC training. This could, therefore prevent the generalizability of the results obtained in this study.

\section{CONCLUSION}

The IPC had much relevance at the period it was conducted. Improvement of knowledge was observed after the IPC training among PMV. Trainings on COVID-19 preventive practices among PMV should not be a one-off event. Rather, repeat sessions of such trainings should be organized to keep PMV abreast of current protocols needed to prevent COVID-19. Also, modalities for the scheduled evaluation of knowledge gained from such trainings should be developed through PMV association. Also, PMV should be empowered to sensitize and educate their clients on the prevention of COVID-19 and link them to testing when required.

\section{ACKNOWLEDGEMENT}

The authors are grateful to all the patent medicine vendors who participated in this study.

\section{FUNDING}

The authors have received no funding for conducting this study or preparation and submission of this manuscript.

\section{AUTHORS CONTRIBUTIONS}

Ilesanmi OS conceptualized the study. Ilesanmi OS and Fakayode OE supervised data collection. Ilesanmi OS and Afolabi AA analyzed the data. Afolabi AA drafted the manuscript. All authors reviewed, vitally revised, and agreed on the final version of the manuscript prior to submission.

\section{CONFLICT OF INTERESTS}

Authors declare no conflict of interest.

\section{REFERENCES}

1. Ilesanmi OS, Akande A, Afolabi AA. Overcoming COVID-19 in West African countries: Is herd immunity an option? Pan Afr Med J 2020;35:103.

2. Cherumanalil JM, Thayyil J. Pharmacoloical treatments of COVID-19: a review. Asian J Pharm Clin Res 2020;13:16-22.

3. Sasmi MB, Jose M, Kuttichira P. Current therapeutic options for coronavirus disease-2019-a pharmacological review. Asian J Pharm Clin Res 2020;13:42-50.

4. Quadrie ZL, Wani Shahid UD, Gautam SP, Khan KA. Outbreak, epidemiology, therapeutics and prevention of coronavirus disease-2019: a review. Int J Curr Pharm Res 2020;12:1-4.

5. Ilesanmi 0 , Afolabi A. Perception and practices during the COVID-19 pandemic in an urban community in Nigeria: a crosssectional study. Peer J 2020;8:e10038.

6. European Centre for Disease Control. COVID-19 situation update worldwide; $2020 . \quad$ Available from: https://www.ecdc.europa.eu/en/geographical-distribution2019-ncov-cases. [Last accessed on 05 Nov 2020]

7. Adeloye D, David RA, Olaogun AA, Auta A, Adesokan A, Gudanya $\mathrm{M}$, et al. Health workforce and governance in Nigeria. Hum Res Health 2017;15:32. 
8. Worldometer. Nigeria Population; 2020. Available from: https://www.worldometers.info/world-

population/nigeria/nigeria-population/. [Last accessed on 21 Oct 2020]

9. Ilesanmi OS, Afolabi AA. Home-based care in the management of COVID-19 in Nigeria. Ibom Med J 2021;14.

10. Beyeler N, Liu J, Sieverding MA. Systematic review of the role of proprietary and patent medicine vendors in healthcare provision in Nigeria. PLoS One 2015;10:e0117165.

11. Durowade KA, Bolarinwa OA, Fenenga CJ, Akande TM. Operations and roles of patent and proprietary medicine vendors in selected rural communities in edu local government Area, Kwara State, North-Central Nigeria. J Com Med Prim Health Care 2018;30:75-89.

12. Treleaven E, Liu J, Prach LM, Isiguzo C. Management of pediatric illnesses by patent and proprietary medicine vendors in Nigeria. Malar J 2015;14:232.

13. Liu J, Prach LM, Treleaven E, Hansen M, Anyanti J, Jagha T, et al. The role of drug vendors in improving basic health-care services in Nigeria. Bull World Health Organ 2016;94:267-75.
14. Prach LM, Treleaven E, Isiguzo C, Liu J. Care-seeking at the patent and proprietary medicine vendors in Nigeria. BMC Health Serv Res 2015;15:1-12.

15. Sieverding M, Liu J, Beyeler N. Social support in the practices of informal providers: the case of patent and proprietary medicine vendors in Nigeria. Soc Sci Med 2015;143:17-25.

16. Ilesanmi OS, Afolabi AA. In search of the true prevalence of COVID-19 in Africa: Time to involve more stakeholders. Int J Health Sci 2020:e108105.

17. City Population-statistics, maps, and charts. Kwara state in Nigeria. Available from: https://citypopulation.de/php/nigeria-admin.php? adm1id=NGA024. [Last accessed 21 Oct 2020]

18. Britannica. Kwara state, Nigeria. Available from: https://www.britannica.com/place/Kwara. [Last accessed on 21 Oct 2020].

19. Ilesanmi OS, Afolabi AA. Six months of COVID-19 response in Nigeria: lessons, challenges, and way forward. JID Health 2020;3(Special 1):198-200.

20. Auta A, Omale S, Folorunsho TJ, David S, Banwat SB. Medicine vendors: self-medication practices and medicine knowledge. $\mathrm{N}$ Am J Med Sci 2012;4:24-8. 